\title{
Women's Knowledge and Attitudes about Complications during Pregnancy and Childbirth in Guinea
}

\author{
Mamadou Dioulde Balde ${ }^{1 *}$, Aissatou Diallo1, Amadou Oury Touré1, Anne Marie Soumah1, \\ Alpha Oumar Sall ${ }^{1}$, Sadan Camara ${ }^{1}$, Ousmane Balde ${ }^{2}$, Ramata Diallo¹, Alpha Amadou Barry ${ }^{1}$ \\ ${ }^{1}$ Center for Research in Reproductive Health in Guinea/Cellule de Recherche en Santé de la Reproduction en Guinée \\ (CERREGUI), Conakry, Guinea \\ ${ }^{2} \mathrm{CHU}$ Donka, Clinique de Gynécologie et Obstétrique, Conakry, Guinea \\ Email: *baldemddka@gmail.com
}

How to cite this paper: Balde, M.D., Diallo, A., Touré, A.O., Soumah, A.M., Sall, A.O., Camara, S., Balde, O., Diallo, R. and Barry, A.A. (2021) Women's Knowledge and Attitudes about Complications during Pregnancy and Childbirth in Guinea. Open Journal of Obstetrics and Gynecology, 11, 1291-1305.

https://doi.org/10.4236/ojog.2021.1110120

Received: August 19, 2021

Accepted: October 5, 2021

Published: October 8, 2021

Copyright $\odot 2021$ by author(s) and Scientific Research Publishing Inc. This work is licensed under the Creative Commons Attribution International License (CC BY 4.0).

http://creativecommons.org/licenses/by/4.0/ (c) (i) Open Access

\begin{abstract}
Introduction: Maternal mortality remains a major public health problem in the world. Complications during pregnancy and childbirth are the main causes of maternal mortality in low-income countries. It is estimated that $15 \%$ of deaths are related to these complications. Studies have shown that women have little or no acquaintance on sign danger and complications during pregnancy and childbirth. Limited literature exists on women's knowledge and attitudes about pregnancy and childbirth's complications as well as the barriers for their management, therefore necessity to carry out this study. Objective: To explore women's knowledge and attitudes in the community about complications during pregnancy and childbirth. Method: A qualitative study was conducted in three prefectures of Guinea. Eighteen focus groups were conducted with women of reproductive age living in urban and rural areas. Results: Complications during pregnancy and childbirth are common among pregnant women in Guinea. Many women have knowledge about various sorts of complications related to pregnancy and childbirth. These complications were mostly vaginal bleeding, abortions and maternal mortality. The use of a health facility in case of complications during pregnancy and childbirth was reported as a major attitude in this study. Accompanying the woman to the health facility was another attitude identified. Lack of financial means, the distance from the health facilities and the lack of means of transport were listed as barriers to the management of complications during pregnancy and childbirth. Conclusion: This study showed that women's knowledge and attitudes about obstetric complications are insufficient. To that effect, women counselling during prenatal consultations on the risks of complications and
\end{abstract}


especially the identification of sign danger during pregnancy and childbirth is essential to reduce maternal and neonatal mortality in our less equipped countries.

\section{Keywords}

Complications, Pregnancy, Childbirth, Knowledge, Attitude, Guinea

\section{Introduction}

Maternal mortality remains a major public health problem in the world. It is estimated that more than a quarter of maternal deaths occur each year in the world. The majority of these deaths occur in low-income countries and sub-Saharan Africa is the most affected region by this phenomenon [1]. In Guinea, it is 550 deaths per 100,000 living births [2]. The main causes of maternal mortality in the low-income countries are complications during pregnancy and childbirth. It is estimated that $40 \%$ of women experienced complications during pregnancy and $15 \%$ of these are fatal [3] [4] [5]. However, most maternal deaths can be prevented if women receive good quality care in time. Several studies in Africa have shown that women have little knowledge of complications during pregnancy, childbirth and the postpartum period [6] [7] [8]. However knowledge and management of these complications are one of the strategies that can reduce maternal mortality. The scarcity of data in the on the women's knowledge literature and attitudes concerning complications during pregnancy and childbirth, especially in low-income countries such as Guinea, motivated this study.

\section{Objective of the study}

Explore women's knowledge and attitudes towards complications during pregnancy and childbirth.

Specific objectives:

1) Describe the extent of complications related to pregnancy and childbirth.

2) To explore women's knowledge of pregnancy and childbirth complications

3) Describe women's attitudes towards complications in pregnancy and childbirth.

4) Determine the constraints on the use of health services during complications in pregnancy and childbirth.

\section{Study setting}

Republic of Guinea is a coastal country in the West African region, covering an area of $245,857 \mathrm{~km}^{2}$. It is divided into four natural regions and seven administrative regions and the special zone of Conakry. Its population is estimated at $12,877,894$ in 2021 . The total fertility rate is 4.8 children per woman. Only $35 \%$ of women completed the four antenatal care (ANC). More than half (53\%) of childbirth took place in a health facility and $55 \%$ of women gave birth with the assistance of skilled personnel [2]. 


\section{Methods}

This is a qualitative cross-sectional study of women aged 15 - 49 years in the community.

Study sites: To ensure representativeness at the national level, the study was carried out in three prefectures in the different natural regions: Mamou, Dabola and Lola

Sampling: A random draw was carried out using software to select a rural area in each prefecture. The selection of Focus group discussion (FGD) participants was also carried out with the help of a community guide and local women's associations.

Data collection techniques: 18 focus group discussions with married and unmarried women and girls in the community (9 in rural areas and 9 in urban areas) were conducted during the period September to October 2014. The FGD guide covers the extent of complications during pregnancy and childbirth, types of complications, where to seek care in case of complications and constraints related to the management of complications.

Data analysis: The data were analyzed using the strategic assessment technique developed by WHO/HRP with the use of similarity and difference tables [9].

Ethics: The study protocol was submitted and validated by the Guinean Health Research Ethics Committee. Informed consent was obtained from the participants prior to data collection and confidentiality of the information collected was guaranteed throughout the process.

\section{Results}

Table 1 shows that women in the 20 - 24 age group represent $1 / 3$ of the study population, followed by adolescents aged 15 - 19. Almost half (49.4\%) of the women had no education, with a higher frequency in rural areas (54.8\%). Housewives $(29.2 \%)$, followed by pupils/students $(20.1 \%)$. It should be noted that two-thirds of the participants were married.

Table 1. Socio-demographic characteristics of FGD participants.

\begin{tabular}{lcccccc}
\hline & $\begin{array}{c}\text { Urbain } \\
(\mathrm{N}=83)\end{array}$ & $\%$ & $\begin{array}{c}\text { Rural } \\
(\mathrm{N}=73)\end{array}$ & $\%$ & $\begin{array}{c}\text { Total } \\
(\mathrm{N}=154)\end{array}$ & $\%$ \\
\hline Age & & & & & & \\
$15-19$ Years & 16 & 19.8 & 24 & 32.9 & 40 & 26.0 \\
$20-24$ & 18 & 34.6 & 23 & 31.5 & 51 & 33.1 \\
$25-30$ & 22.2 & 13 & 17.8 & 31 & 20.1 \\
$31-35$ & 4 & 4.9 & 7 & 9.6 & 11 & 7.1 \\
$36-40$ & 13 & 16.0 & 3 & 4.1 & 16 & 10.4 \\
$41-45$ & $\mathbf{2 1}$ & 100 & $\mathbf{7 3}$ & 100 & $\mathbf{1 5 4}$ & $\mathbf{1 0 0}$ \\
\hline
\end{tabular}




\section{Continued}

Educational level

Any

Primary

Secondary

Professional

Superior

Total

$\begin{array}{llllll}36 & 44.4 & 40 & 54.8 & 76 & 49.4\end{array}$

ccupation

Housewife

Pupil/Student

Dressmaker

Trader

Cultivator

Teacher/Health worker

Hairdresser

Others

Total

$\begin{array}{llllll}17 & 21.0 & 14 & 19.2 & 31 & 20.1\end{array}$

$\begin{array}{lllllll}21 & 25.9 & 17 & 23.3 & 38 & 24.7\end{array}$

$\begin{array}{llllll}3 & 3.7 & 0 & 0 & 3 & 1.9\end{array}$

$4.9-2$

$\begin{array}{lll}2.7 & 6 & 3.9\end{array}$

$81 \quad 100$

$100 \quad 154 \quad 100$

Marital status

$\begin{array}{lcccccc}\text { Unmarried } & 27 & 33.3 & 24 & 32.9 & 51 & 33.1 \\ \text { Mariée } & 52 & 64.2 & 48 & 65.8 & 100 & 64.9 \\ \text { Married } & 1 & 1.2 & 0 & 0 & 1 & 0.6 \\ \text { Divorced } & 1 & 1.2 & 1 & 1.4 & 2 & 1.3 \\ \text { Total } & \mathbf{8 1} & \mathbf{1 0 0} & \mathbf{7 3} & & 154 & 100\end{array}$

Number of living children

\begin{tabular}{lcccccc}
$0-2$ & 52 & 64.2 & 55 & 75.3 & 107 & 69.5 \\
3 à 5 & 20 & 24.7 & 16 & 21.9 & 36 & 23.4 \\
6 et plus & 9 & 11.1 & 2 & 2.7 & 11 & 7.1 \\
Total & $\mathbf{8 1}$ & $\mathbf{1 0 0}$ & $\mathbf{7 3}$ & $\mathbf{1 0 0}$ & $\mathbf{1 0 4}$ & $\mathbf{1 0 0}$ \\
\hline
\end{tabular}

The analysis of the results focused on women's knowledge, complications and their attitudes. The main constraints in the management of these will then be discussed.

\subsection{Knowledge}

The results of the study show that in the visited communities, interviewed women had knowledge about the extent and types of complications related to pregnancy and childbirth.

1) Magnitude of complications

The focus groups conducted with women in urban and rural areas showed 
that complications related to pregnancy and childbirth often occur among women in their respective localities. For example, a 21-year-old unmarried girl living in an urban center said:

"Yes, there are many complications related to pregnancy and childbirth.".

This is also the opinion of a young girl living in a rural area:

"Nowadays, pregnant women suffer a lot during pregnancy. For example, my uncle's wife had some issues during her fourth pregnancy; she often complained of stomaches, her feet swelled to the point that she could not even wear some of her shoes, she had walking issue and finally the doctor at their health center referred her to the hospital for treatment. Also, our neighbor's wife is two months pregnant, she complains of back pain, she vomits all the time and gets dizzy so she can't even stop; she is in bed all the time".

The extent of the complications frightens even newly married girls, as illustrated by these words from a young woman living in an urban center:

"I have not yet had a child, but I often hear people saying that when a woman gets pregnant, she becomes very fragile and she has to be very careful and go to hospital each time to reassure herself of her health and her child. Because if she doesn't go to the hospital for the check-up, she risks bleeding during the childbirth. If she bleeds too much she will be very fragile and may die or lose her child".

\section{2) Types of complications}

The participants reported several types of complications related to pregnancy and childbirth: anemia, vaginal bleeding, abortion, maternal and infant mortality.

An adult woman, living in an urban area, insisted on the cases of bleeding during pregnancy:

"During pregnancy, many women complain of heavy and frequent bleeding. In my family, some pregnant women suffer from this; they lose a lot of blood, weight and become weak. Our husbands, sisters, brothers and cousins regularly donate blood because there is none here. Despite the commitment of all the parents, some women unfortunately die as a result of blood loss".

As some women reported, one participant mentioned cases of dizziness and oedema of the lower limbs:

"Yes, there are a lot of complications during pregnancy and childbirth. My first pregnancy made me too tired, I was always getting sick; I often vomited; sometimes I felt dizzy and my feet swelled up. Then my husband went to work, so he had to swap with my mum so that she could look after me at home".

Faced with unwanted pregnancies, some girls induce abortions, leading to 
numerous complications and even death. As this young woman in a rural area testifies:

"Yes, there are cases of induced abortions. In our locality, there are young girls who get pregnant without being married; faced with this situation, they have abortions which become complicated and often lead to their death. Some take decoctions to remove the pregnancy".

Another woman living in an urban area also persisted on the commitment of abortions:

"Among us here... young girls get pregnancies that they can't handle and they resort to abortion during which they may die. Then there are infections and even a frequent lack of blood".

Complications that can lead to stillbirths, premature deliveries, obstetric fistulas, infections and back pain were cited to a lesser extent by some participants.

It is worth noting that Caesarean section was reported by many participants as a complication of pregnancy and childbirth, like this young women in urban area:

"Currently caesarean section is much higher among young girls because most of our peers who got pregnant had surgery".

To prevent complications related to pregnancy and childbirth, participants insisted on the importance of prenatal consultation:

"Yes, there are many complications related to pregnancy and childbirth. If a woman is pregnant, especially for the first time, if she doesn't have an antenatal care (ANC), she can have a lack of blood. Some women bleed during or even after delivery; others have seizures. You see, all these cases can cause the death of the woman or her child".

\subsection{Attitudes}

\section{1) Attitudes towards complications in the pregnancy}

Most women with complications go first to the health center. They are referred to the higher structure according to the case and the level of care of the host structure, as this young woman reports:

"One day, I accompanied a neighbor who was pregnant to the health center. In fact, she was dizzying and fell down; after consultation, the doctors told us that her blood pressure was very high (hypertension). They referred us directly to the prefectural hospital because she needs emergency care, including an ultrasound to find out the condition of the baby."

On the other hand, some go directly to the hospital in case of complications during the pregnancy:

"When there are complications during pregnancy, most women go to the 
health centers and others go directly to the prefectural hospital where they feel they will be better taken care of".

However, despite the risks they run, some women prefer to be treated at home by a traditional birth attendant for reasons of personal trust or the low cost of the services.

According to a young single woman in rural area:

"Families who cannot afford the cost of treatment at the health center or to go to the hospital in town, they call on traditional doctors to treat complications".

\section{2) Attitude towards complications during childbirth}

Health centers and hospitals were mentioned by the participants as places where they could go in case of complications during childbirth.

The words of these participants in rural and urban areas are illustrative:

"Hey me, only God saved me, during the childbirth of my second child I had abdominal pain for two days. When it started, I went to the health center, but the doctor told me to go home because the moment of childbirth is still far away. It was only the next night that the pain became very intense. As I am far from the health center my aunt sent me to an old lady to give birth. After the childbirth I bled a lot because the child was huge and I was urgently evacuated to the hospital in Dabola. I had even lost conscious, and it was only after the treatment that I recovered. Since then I am even afraid of having another child".

Accompaniment by a relative during childbirth is another attitude adopted by the family environment to support the woman:

"Hee hee hee! I remember I once accompanied my sister to give birth at the health center, she had suffered a lot because the baby was huge, which meant she lost a lot of blood; so the doctor said to go to the city in the big hospital so that she could benefit from blood".

Some women testified that women who suffer complications with traditional birth attendants or home-based midwives are taken to health facilities for better care:

"There is an old traditional birth attendant, I got my child with her, but I suffered a lot, during the childbirth I had tears me and we had to go to the hospital to repair them. She told us to go to hospital quickly because she can't handle it".

\subsection{Barriers in Management of Complications during Pregnancy and Childbirth}

With regard to complications during pregnancy, lack of financial means, distance and the lack of medication were identified as the main constraints. In addition, long hours waiting, poor reception and the unavailability of health care 
personnel were identified as constraints.

\section{1) Financial constraints}

These constitute a major handicap and are in contradiction with the principle of "free care during pregnancy and childbirth" stated by the authorities. These relate to the cost of medicines, travel and care.

In this regard, one woman reports:

"The major issue we have here is lack of financial means and medicines. Whether at the health center or the hospital, wherever you go, they ask for money and if you don't have it they won't even look at you, even though we were told that pregnant women should not have to pay for anything; but here it's the other way around".

This is also the opinion of the participants who insist on the weight of financial constraints in the management of complications during childbirth:

"Many women die here, I would say it is because of lack of money. I remember well I have a niece who gave birth with an old woman, after she had a crisis and the old woman told us to send her to the health center. When we arrived, the doctor prescribed medication and her husband didn't have enough money that day, so we told the doctor to do the treatment and then we would send the rest of the money, but he told us that the medication was not for him. She survived with difficulty; you can see the issue we have in our village".

\section{2) Distance and transportation options}

Women with complications face barriers related to geographical accessibility. Indeed, the state of the roads and the distance between the localities and the health structures are the causes of the scarcity and lack of appropriate means of transport, thus leading to the frequent use of motorbikes. These different factors can be a barrier for the movement of pregnant women to health facilities, leading to delays in treatment and maternal and/or neonatal deaths.

A young woman aged 15 living in a rural area stated that:

"Here we have huge issues in case of complications. We don't have an ambulance, so if we have to go to the prefectural hospital we have either to take a motorbike or look for a vehicle, which is hard to find. Vehicles rarely come here, and most of the time it is on market day that they are numerous. Another thing is that our health center does not have blood in stock for the treatment of complications in pregnant women, so if we need it we have to go to the prefectural hospital. All this requires money, but we only live from agriculture".

\section{3) Lack of medicine, medical equipment and blood storage}

The treatment of complications during pregnancy and childbirth requires the availability of medicines. Women report frequent shortages of medicines in the health facilities; this is a result of the delay in treating the woman, who is obliged 
with her family to mobilize resources to buy the products. Indeed, one urban participant reports the following precision:

"We don't get any medicine from the hospital here, normally they have to send a lot of free medicines for women with complications during pregnancy and childbirth to the health facilities in our locality".

The participants reported also lack of medical equipment in the maternal health services for managing possible complications during childbirth. One rural woman explained that:

"As they have just said, medicines are expensive and we don't have husbands who pay for us, and if we have to do a surgery, the doctors tell you that they don't have the materials".

In addition, there are difficulties related to the availability of blood in case of severe bleeding or acute anemia, which were mentioned in some localities. There is no possibility of storing blood (blood bank) in certain prefectural hospitals. Thus, an adult woman from an urban area stated that:

"We have serious issues with blood shortages. I remember well when my little sister gave birth and the doctors asked her to be transfused. It was difficult to get the blood because there was no blood available in the hospital. So we had to send two people who gave blood so that my little sister's life could be saved".

\section{4) Constraints related to health care providers}

Poor reception and long hours waiting were reported to be a discouraging factor in the use of health services, especially for women who come to the health facilities for complications related to pregnancy or childbirth. This is compounded by the abandonment and mistreatment of these women in the maternal health services.

Further, one-woman reports:

"Sometimes when you come to the hospital for a pregnancy complication, there are agents who do not welcome you properly, they leave you there for a long time before looking at you and that is not good for pregnant women".

Similarly, participants in the urban and rural areas visited reported that:

"Sometimes when you bring a woman for childbirth and she has complications, the agents don't deal with you quickly. They spend all their time shouting at you, some don't treat us well there and it is often these issues that make us very tired".

In addition, single women who contract unwanted pregnancies are discriminated against. They feel marginalized in some health facilities, especially when they have pain. Faced with this state of affairs, a young girl from an urban area 
said:

"If you go to the doctors, you are pregnant, you are suffering and you are not married, they don't even look at you, especially if you don't have any money.".

The study showed that at late hours, health workers are not available in the health facilities. This may be due to insufficient health personnel or to poor organization of the team in place. This can have negative consequences for complications related to pregnancy and childbirth, which often occur at late hours.

A participant living in a rural area stated that:

"In case of complications, it is really difficult, women can go to the health center at night, but they cannot find the health workers there. They are forced to go to the home of the midwife who is in our village".

\section{Discussion}

\section{1) Knowledge}

Complications during pregnancy and childbirth represent a major challenge in preventing maternal and infant mortality. This study shows that these complications are important in Guinea. El-Nagar A.E. et al. also found a very high rate (80.5\%) in Egypt [4]. In contrast, Kebede et al reported a much lower prevalence (15.9\%) in Ethiopia [10].

Anemia, vaginal bleeding, abortion, maternal, neonatal and infant mortality were the main types of complications cited by the participants in our study. Bleeding during pregnancy, childbirth and postpartum is the most well-known complication according to other authors [4] [11]-[16]. In their study, El-Nagar A.E et al reported that vaginal bleeding was the danger sign mentioned by almost one third of women during pregnancy and those occurring during labor and postpartum were mentioned by just over one third of participants [4]. Other complications listed were miscarriage and abortion [4] [13], oedema and poor presentation [11] [12] [14] [16] [17]. In addition, prolonged labor [15] [17] and intrauterine fetal death [13] are also listed. Further, high frequencies of headache and fever have also been reported by some authors [10] [14] [17] as well as premature rupture of membranes [18].

In a study in Ethiopia, Kebede et al identified a history of hypertension, heart problems and urban lifestyle as factors associated with pregnancy-related complications [10].

Multivariate analyses in quantitative studies have reported that maternal age, education, income, self-care, health service utilization and distance from the facility were determinants of women's knowledge of obstetric danger signs [8] [14] [16] [19]. Other determinants of this knowledge such as place of residence, multiparity, history of surgery and older age of women have been cited [10] [18] [19] as well as the use of antenatal care services [20]. Furthermore, as in our results, marital status is a determinant that should not be underesti- 
mated. Thus Wilander RD et al reported in a study in Indonesia on the determinants of knowledge of danger signs during pregnancy that women who were married or living with their partner were 1.914 times more likely to identify these danger signs than unmarried women or those who were single or never in a relationship [19].

\section{2) Attitudes}

Our study found that the predominant attitude of women in the community when faced with signs of complications during pregnancy is to go to the local health facility. Studies in Egypt and Ghana also reported that the vast majority of women consulted a health provider when faced with danger signs or complications [4] [21]. The use of traditional birth attendants was cited by a minority of our participants and by other authors [17].

The importance of prenatal consultation was emphasized to prevent complications during pregnancy and childbirth. Mekonnen et al report that $72.6 \%$ of mothers had a positive attitude towards preventing obstetric danger signs during pregnancy [11]. In Papua New Guinea, 53.6\% of women received information about danger signs during ANC [16].

Another attitude identified by the participants in this study was that a relative should accompany the woman in case of complications during pregnancy or childbirth. It represents a major psychological support for the woman in labor [22]. According to Peprah et al. [21], acceptance of support is easier when the delivery is carried out by a traditional birth attendant.

3) Barriers in the management of complications during pregnancy and childbirth

The main constraints identified during this study are lack of financial means, distance between facilities and homes, and the cost of transport. Lack of financial means has also been observed in other studies. It concerns the cost of care for women in health facilities [12] [15] [23] [24] and the cost of transport [12] [24]. In addition, the distance between the home and the health facility as well as the lack of appropriate means of transport have also been reported by other authors [12] [15] [23] [24] [25].

Another constraint also identified is the poor attitude of health care staff in the form of poor reception and long waiting times, as highlighted by other studies [12]. It is in this context that Ochieng et al emphasized the fear of reprimand by health workers. The negative attitude of health workers explains the pervasive fear expressed by the participants. The main constraints identified during this study are the lack of financial means, the distance between the facilities and the homes, and the cost of transport. The lack of financial means has also been observed in other studies. It concerns the cost of caring for women in health facilities [12] [15] [23] [24] and the cost of transport [12] [24]. In addition, the distance between the home and the health facility as well as the lack of appropriate means of transport have also been reported by other authors [12] [15] [23] [24] [25]. 
Another identified barrier is the poor attitude of health care providers in the form of poor reception and long waiting times, as highlighted by other studies [12]. It is in this context that Ochieng et al. emphasized the fear of reprimand by health workers. The negative attitude of health workers explains the pervasive fear expressed by the participants [25].

Based on the three classic delays in medical management constraints, Geleto A et al. summarize in a systematic review, these different barriers to access and use of emergency obstetric care. The main barriers identified in relation to the first delay included young age, illiteracy, lower income, unemployment and poor use of health care facilities. In addition, we have women's lower level of self-affirmation, poor knowledge of danger signs and cultural beliefs. The second delay was due to poor roads, lack of vehicles, cost of transport and distance from health facilities. Barriers related to the third delay included lack of emergency obstetric care services and delivery, lack of trained staff, poor management of emergency obstetric care delivery, cost of services, long waiting time, poor referral practices and poor coordination among staff [24].

\section{Strengths and Limitations of the Study}

This is the first study in Guinea that explored women's knowledge and attitudes about complications during pregnancy and childbirth. It showed that women's knowledge of these obstetric complications is insufficient and that their positive attitudes towards danger signs face many obstacles to their management.

However, the participation of pregnant women in this study would have ensured a more in-depth analysis of the topic. Furthermore, the absence of a quantitative component did not allow for an analysis that could identify the different variables associated with this knowledge and attitude.

\section{Involvement in Research and Practice}

After a formative research using a mixed method that includes pregnant women and health providers that will allow to reinforce the understanding of the theme and to identify an intervention, an implementation research is important to experiment an intervention to improve the knowledge of complications during pregnancy and childbirth. It would thus lead through its scaling up to the adoption of programs and strategies for better management and especially early detection of danger signs. Health care providers should benefit from training modules on the subject. These activities will contribute to providing respectful obstetrical care on the one hand and to reducing maternal mortality on the other hand.

\section{Conclusion}

Complication knowledge during pregnancy and childbirth has a great importance. In our study, vaginal bleeding and anemia were the main forms reported. The main attitude of women towards danger signs and complications is to seek 
help from health facilities. From our results, it appears that the level of knowledge of women is low and information is insufficient. It is therefore important to stimulate the use of antenatal care services and to reinforce information on danger signs and complications during pregnancy and childbirth.

\section{Funding}

This article is a secondary analysis of data from a research study on "Women's Health in Guinea. Situational analysis" which is funded by WHO with MUSKOKA funds in 2014.

\section{Conflicts of Interest}

The authors declare no conflicts of interest regarding the publication of this paper.

\section{References}

[1] Araya, W.N. (2013) Knowledge and Practice of Reproductive Health among Mothers and Their Impact on Fetal Birth Outcomes: A Case of Eritrea. University of South Florida, Tampa, FL.

[2] Institut National de la Statistique Ministère du Plan et du Développement Economique Conakry, Guinée (2019) Enquête Démographique et de Santé 2018. Conakry, July 2019.

[3] Endeshaw, D.B., Gezie, L.D. and Yeshita, H.Y. (2018) Birth Preparedness and Complication Readiness among Pregnant Women in Tehulederie District, Northeast Ethiopia: A Community-Based Cross-Sectional Study. BMC Nursing, 17, Article No. 10. https://doi.org/10.1186/s12912-018-0278-y

[4] El-Nagar, A.E., Ahmed, M.H. and Belal, G. (2017) Knowledge and Practices of Pregnant Women Regarding Danger Signs of Obstetric Complications. Journal of Nursing and Health Science, 6, 30-41.

[5] World Health Organization (2007) Managing Complications in Pregnancy and Childbirth: A Guide for Midwives and Doctors. World Health Organization.

[6] Amenu, G., Mulaw, Z., Seyoum, T. and Bayu, H. (2016) Knowledge about Danger Signs of Obstetric Complications and Associated Factors among Postnatal Mothers of Mechekel District Health Centers, East Gojjam Zone, Northwest Ethiopia, 2014. Scientifica, 2016, Article ID: 3495416. https://doi.org/10.1155/2016/3495416

[7] Kabakyenga, J.K., Östergren, P., Turyakira, E. and Pettersson, K.O. (2011) Knowledge of Obstetric Danger Signs and Birth Preparedness Practices among Women in Rural Uganda. Reproductive Health, 8, Article No. 33. https://doi.org/10.1186/1742-4755-8-33

[8] Geleto, A., Chojenta, C., Musa, A. and Loxton, D. (2019) WOMEN's Knowledge of Obstetric Danger Signs in Ethiopia (WOMEN's KODE): A Systematic Review and Meta-Analysis. Systematic Reviews, 8, Article No. 63. https://doi.org/10.1186/s13643-019-0979-7

[9] World Health Organization. (2007) The WHO Strategic Approach to Strengthening Sexual and Reproductive Health Policies and Programmes. World Health Organization.

[10] Kebede, Z.T., Yigezaw, G.S., Yilma, T.M. and Delele, T.G. (2021) Prevalence of Pregnancy-Related Complications and Associated Factors among Reproductive-Aged 
Women in Northwest Ethiopia: A Community-Based Retrospective Cross-Sectional Study. International Journal of Gynecology \& Obstetrics, 154, 62-71. https://doi.org/10.1002/ijgo.13516

[11] Mekonnen, T., Girmaye, B. and Taye, F. (2018) Assessment of Knowledge and Attitude towards Obstetric Danger Signs during Pregnancy among Pregnant Mothers Attending Antenatal Care in Mizan Aman Public Health Facilities, Bench Maji Zone, South West Ethiopia. Journal of Gynecology and Women's Health, 11, Article No. 555813. https://doi.org/10.19080/JGWH.2018.11.555813

[12] Liambila, W.N. and Kuria, S.N. (2014) Birth Attendance and Magnitude of Obstetric Complications in Western Kenya: A Retrospective Case-Control Study. BMC Pregnancy and Childbirth, 14, Article No. 311.

https://doi.org/10.1186/1471-2393-14-311

[13] Gobran, M.A., Fatah, M.T.A., Ramadan, M.S., Amer, G.A., Rabeh, M.M., Elshafei, R.M., et al. (2021) Educational Program for Pregnant Women Regarding Obstetrics Dangerous Signs in Rural Areas. Open Journal of Obstetrics and Gynecology, 11, 529-552. https://doi.org/10.4236/ojog.2021.115050

[14] Mwilike, B., Nalwadda, G., Kagawa, M., Malima, K., Mselle, L. and Horiuchi, S. (2018) Knowledge of Danger Signs during Pregnancy and Subsequent Healthcare Seeking Actions among Women in Urban Tanzania: A Cross-Sectional Study. BMC Pregnancy and Childbirth, 18, Article No. 4.

https://doi.org/10.1186/s12884-017-1628-6

[15] Worku, A.G., Yalew, A.W. and Afework, M.F. (2013) Maternal Complications and Women's Behavior in Seeking Care from Skilled Providers in North Gondar, Ethiopia. PLoS ONE, 8, e60171. https://doi.org/10.1371/journal.pone.0060171

[16] Vallely, L.M., Emori, R., Gouda, H., Phuanukoonnon, S., Homer, C.S.E. and Vallely, A.J. (2019) Women's Knowledge of Maternal Danger Signs during Pregnancy: Findings from a Cross-Sectional Survey in Papua New Guinea. Midwifery, 72, 7-13. https://doi.org/10.1016/j.midw.2019.02.001

[17] Teshoma Regasa, M., Markos, J., Habte, A. and Upashe, S.P. (2020) Obstetric Danger Signs: Knowledge, Attitude, Health-Seeking Action, and Associated Factors among Postnatal Mothers in Nekemte Town, Oromia Region, Western Ethiopia-A Community-Based Cross-Sectional Study. Obstetrics and Gynecology International. 2020, Article ID: 6573153. https://doi.org/10.1155/2020/6573153

[18] Tamang, S.T., Dorji, T., Yoezer, S., Phuntsho, T. and Dorji, P. (2021) Knowledge and Understanding of Obstetric Danger Signs among Pregnant Women Attending the Antenatal Clinic at the National Referral Hospital in Thimphu, Bhutan: A CrossSectional Study. BMC Pregnancy and Childbirth, 21, Article No. 104. https://doi.org/10.1186/s12884-021-03580-4

[19] Wulandari, R.D. and Laksono, A.D. (2020) Determinants of Knowledge of Pregnancy Danger Signs in Indonesia. PLOS ONE, 15, e0232550. https://doi.org/10.1371/journal.pone.0232550

[20] Maseresha, N., Woldemichael, K. and Dube, L. (2016) Knowledge of obstetric Danger Signs and associated Factors among Pregnant Women in Erer District, Somali Region, Ethiopia. BMC Women's Health, 16, Article No. 30. https://doi.org/10.1186/s12905-016-0309-3

[21] Peprah, P., Abalo, E.M., Nyonyo, J., Okwei, R., Agyemang-Duah, W. and Amankwaa, G. (2018) Pregnant Women's Perception and Attitudes toward Modern and Traditional Midwives and the Perceptional Impact on Health Seeking Behaviour and Status in Rural Ghana. International Journal of Africa Nursing Sciences, 8 , 66-74. https://doi.org/10.1016/j.ijans.2018.03.003 
[22] Balde, M.D., Nasiri, K., Mehrtash, H., Soumah, A., Bohren, M.A., Irinyenikan, T.A., et al. (2020) Labour Companionship and Women's Experiences of Mistreatment during Childbirth: Results from a Multi-Country Community-Based Survey. BMJ Global Health, 5, e003564. https://doi.org/10.1136/bmjgh-2020-003564

[23] Raymondville, M., Rodriguez, C.A., Richterman, A., Jerome, G., Katz, A., Gilbert, H., et al. (2020) Barriers and Facilitators Influencing Facility-Based Childbirth in Rural Haiti: A Mixed Method Study with a Convergent Design. BMJ Global Health, 5, e002526. https://doi.org/10.1136/bmjgh-2020-002526

[24] Geleto, A., Chojenta, C., Musa, A. and Loxton, D. (2018) Barriers to Access and Utilization of Emergency Obstetric Care at Health Facilities in Sub-Saharan Africa: A Systematic Review of Literature. Systematic Reviews, 7, Article No. 183.

https://doi.org/10.1186/s13643-018-0842-2

[25] Ochieng, C.A and, Odhiambo, A.S. (2019) Barriers to Formal Health Care Seeking during Pregnancy, Childbirth and Postnatal Period: A Qualitative Study in Siaya County in Rural Kenya. BMC Pregnancy and Childbirth, 19, Article No. 339. https://doi.org/10.1186/s12884-019-2485-2

\section{Abbreviations}

ANC (Antenatal care),

FGD (Focus group discussions). 